Introduction In spite of living in tropical climates, vitamin D3 deficiency is evident in urban.

Indian population as a corporate lifestyle disorder; Office executives especially, are not exposed to sunlight due to changing lifestyles and long working hours. Incidence of vitamin B12 deficiency is observed to be high, due to predominantly vegetarian diets and insufficient consumption of dairy products, etc.

Methods This study was conducted at Occupational Health Centre, Hazira from September 2016 to January 2017. In the first phase, 300 executives were surveyed and subjected to analysis of blood levels of vitamin D3 and Vitamin B12.History of exposure to sunlight, exercise, dietary habits, medication etc. was obtained through a Screening Questionnaire before blood collection. In second phase, treatment was advised for three months including counselling for dietary modifications, increased sun exposure, etc. At the end of three months, repeat testing of Vitamins was done to assess the effectiveness.

Results $17.67 \%$ had vitamin B12 deficiency, $17.33 \%$ had vitamin D3 deficiency. Deficient vitamin B12 values were found in 53 subjects of which $61.5 \%$ were vegetarians, $39.5 \%$ nonvegetarians and $30.18 \%$ were having alcohol consumption. Deficient vitaminD3 values were found in 52 subjects of which $92 \%$ do not spend at least $10 \mathrm{~min}$ a day in sun without sunscreen. In second phase 51.62\% had normal Vitamin D3 levels as compared to $8.33 \%$ in first phase and $92.95 \%$ had vitamin B12 levels normal in second phase as compared to $77.1 \%$ in first phase.

Conclusion Effectiveness of oral supplementation of B12/D3 is demonstrated by the results of the second phase of the survey. Increase in sun exposure, dietary modification and other lifestyle modifications were also effective. Office executives need to exercise outdoors and thus increase their exposure to sunlight to facilitate vitamin D absorption. Vitamin B12/D3 tests to be made a part of annual medical check up.

\section{MUSCULOSKELETAL DISORDER AMONG THE GARMENT WORKERS: A MAJOR WORK RELATED HEALTH PROBLEM IN A LEADING GARMENT INDUSTRY OF BANGLADESH}

Siddiqur Rahman*, Samid Siddiquee.

\subsection{6/oemed-2018-ICOHabstracts.461}

Background and objectives Work related musculoskeletal disorders (MSD) accounts for a significant share of post-workday injuries and illnesses and hence constitute a major proportion temporary or permanent disability among garment industry workers in many countries. Bangladesh is now one of the world's leading clothing exporters, and the garment industry employs more than 3.6 million workers in its 4500 factories. However, musculoskeletal disorders become a major health problem for seeking health care and an important cause for absenteeism which is a major concern among owners of the factories and policy makers.

The aim of this study was to estimate the magnitude of musculoskeletal disorders among workers in a large garment industry in Bangladesh.

Methodologies Review of 34264 records of patients attended the outpatient department of the health care centre of the selected garment industry during April 2015 to April 2016 has been done to identify and compute the musculoskeletal disorders in order to calculate the proportion of MSD. A checklist was used to collect data from the outpatient registers.

Results More than 4500 workers are enrolled in the different sections of the selected garment industry. Out of the total 34264 outpatient attendants, 8039 (23\%) sought care for musculoskeletal disorders. On an average 25 MSD patients sought medical help for the management of their health problem. The incidence of MSD in the garment factory is 164.9 per 100 worker years. Of the total patients, 49 cases were referred to the higher level of hospital.

Conclusions Work related MSD is a major health problem among garments workers in Bangladesh, which might cause a significant absenteeism in the work. It is important to identify appropriate intervention including improvement of working environment to prevent MSD among garment workers to sustain the pace of development in this sector.

\section{PRESENTING INJURIES (FARM AND OTHER) AT A REGIONAL HOSPITAL IN VICTORIA, AUSTRALIA - LINKING PREVENTION, PROMOTION AND PLACE}

1,2Susan Brumby, ${ }^{3}$ Muhammad Aziz Rahman, ${ }^{2}$ Nic van Zyl, 'Vanessa Vaughan. 'Deakin University, School of Medicine, Waurn Ponds, Victoria, Australia; ${ }^{2}$ Western District Health Service, National Centre for Farmer Health, Hamilton, Victoria, Australia; ${ }^{3}$ La Trobe Unviersity, School of Nursing and Midwifery, Melbourne, Victoria, Australia

\subsection{6/oemed-2018-ICOHabstracts.462}

Introduction Over the last decade agriculture, forestry and fishing workers had the highest rate of workplace fatalities compared to other occupations in Australia. This is coupled with long distance to both health services and for ambulance assistance. To date, little work has been done on injury prevention at a regional place based level. This study examined the types and causes of farm injuries compared with other injuries presenting to a regional hospital based in an agricultural community in Western Victoria, Australia, with the aim of improving both prevention and care post injury.

Methods A retrospective study of database records was conducted on 41429 patients attending the Accident and Emergency (A and E) Department of a regional hospital in Victoria during 20102015. Data were analysed using SPSS and EXCEL.

Results Most (91\%) of the injuries were related to non-intentional harm accidents. The most common place of injury was the home $(49 \%)$ and one in twelve $(8 \%, n=3314)$ patients identified the place of injury as on-farm. The majority (83\%) arrived by private car. The most common cause of on-farm injuries were: animals (24\%), fall from a farm vehicle (11\%), and materials (11\%) such as nails, needlesticks, timber. Patients who were injured on-farm were more likely to be male compared to injuries from other places $(75 \%$ vs $58 \%$, $\mathrm{p}<0.001$, RR 1.30, 95\% CI: 1.26 to 1.35$)$. Non-intentional harm was more commonly identified among people injured on-farm (99\%) compared to other places $(91 \%) \quad(\mathrm{p}<0.001$, RR 1.08, 95\% CI: 1.07 to 1.09). Patients injured on-farm were more likely to be categorised with higher triage (resuscitation, emergency and urgent) compared to injury at other places $(33 \%$ vs $27 \%, \mathrm{p}<0.001$, RR $1.35,95 \% \mathrm{CI}: 1.20$ to 1.53)

Conclusion This presentation will highlight the most common injuries occurring in a regional community and make recommendations on place-based health promotion/prevention strategies to address both farm and community injuries. 